\title{
Reduced bone mineral content and normal serum osteocalcin in non-steroid-treated patients with juvenile rheumatoid arthritis
}

\author{
Cesare Polito, Ciro Giovanni Strano, Luciana Rea, Maria Alessio, \\ Clemente Servodio Iammarrone, Nicola Todisco, Antonio Marotta, \\ Eugenio Iaccarino, Maria Pirozzi
}

\begin{abstract}
Objectives-To distinguish the effects of juvenile rheumatoid arthritis (JRA) on bone mineralisation from those possibly caused by steroid therapy.

Methods-Bone mineral status was evaluated in 20 children (five boys and 15 girls) with active JRA who never received steroids. Seven had oligoarticular, nine had polyarticular, and four had systemic JRA. Bone mineral content (BMC) was assessed by single beam photon absorptiometry and expressed as a $Z$ score relative to normal values in healthy children. Serum calcium, phosphate, and alkaline phosphatase were measured by colorimetric methods. Whole parathyroid hormone was assayed by Immuno Radiometric Assay. Serum osteocalcin was measured by specific radioimmunoassay. Nutrient intake was assessed by a 24 hours dietary recall. BMC and nutrient intake were also assessed in an age and sex matched control group.

Results-BMC was -1.5 (SEM 0.8) Z scores in patients and $0.4(0.3)$ in the control group $(p=0 \cdot 02)$. BMC averaged -4.9 (2) $Z$ scores in the systemic JRA group, $-1(0.6)$ in the polyarticular goup and $0.3(0.7)$ in oligoarticular JRA patients. Serum calcium, phosphate and osteocalcin values were normal in all patients. No significant difference was found between JRA patients and controls in calcium, phosphate, energy, and protein intake.

Conclusion-JRA subjects have significantly reduced BMC even in the absence of any steroid therapy. Bone demineralisation appears to depend more on disease activity and on reduced motility than on reduced nutrient intake.
\end{abstract}

(Ann Rheum Dis 1995; 54: 193-196)

Children with juvenile rheumatoid arthritis (JRA) are at risk for osteoporosis which may result in vertebral compression and fractures of long bones. ${ }^{1}$ Both corticosteroids in $\mathrm{JRA}^{2}$ and immobilisation in adult rheumatoid arthritis $(\mathrm{RA})^{3}$ have been recognised as causes of osteoporosis. Poor nutrition and decreased appetite, in addition to inadequate sun exposure from decreased outdoor activities, might also affect calcium intake and vitamin $\mathrm{D}$ metabolism and therefore bone mineral content (BMC).

$A$ reduction in $B M C$ has been reported in a number of JRA patients. ${ }^{4-8}$ However, most of the subjects considered were receiving steroid therapy and from the data reported it is not possible to distinguish the effects of steroids from those caused by the disease itself. The report by Lovell et $\mathrm{al}^{4}$ is the only one to suggest that JRA may per se be associated with bone demineralisation. In that study, seven of 15 patients had BMC 2 SD scores below normal and none of the seven was receiving steroid therapy. Unfortunately, no data are available regarding steroid therapy before the study which could have affected bone mass accretion.

In the present paper we report the bone mineral status of patients with JRA who never received steroids. The study was designed in an attempt to isolate the effects of the disease itself on bone from those possibly caused by steroid therapy.

\section{Patients and methods}

The parents of all the children studied gave their informed consent to the inclusion of their offspring before the study commenced.

Bone mineral status was evaluated in 20 children with JRA diagnosed according to the criteria established by the American College of Rheumatology. ${ }^{9}$ The study included five boys and 15 girls, aged $2 \cdot 3$ to 22 years (mean $10 \cdot 7$ (SEM 1-2)). Previous duration of disease at the start of the study was $4.9(0.9)$ years. Four children had systemic (S), nine had polyarticular $(\mathrm{P})$, and seven had oligoarticular $(\mathrm{O})$ JRA. The average age was $16.8(1 \cdot 8)$ years in group $\mathrm{S}, 9(1.4)$ in group $\mathrm{P}$, and 8.8 (2) in group $\mathrm{O}$ patients. All had active disease (joint swelling, tenderness, or both, and functional impairment) and their erythrocyte sedimentation rates were in the range 23-125 mm/1st h. At the time of the study, all patients with systemic JRA had polyarthritis and only one had extra-articular manifestations (lymphoadenomegaly). During the years before the study, all patients with systemic JRA had severe systemic manifestations.

Arthritis of the wrist (at the time of the study or in the past) was recorded in two of four in group $S$ and three of the nine group $P$ patients. None of the children studied was 
taking steroids or had previously received this medication. When examined they were taking non-steroid anti-inflammatory drugs (NSAID) (salicylates, naproxen, indomethacin). Intraarticular steroids had been administered to only one patient with oligoarticular JRA, seven years before the study.

Stature was measured by a wall mounted Harpenden stadiometer and measurements were converted to height standard deviation score (HSDS) according to standards of Tanner and Whitehouse. ${ }^{10}$ These standards have been shown to be similar to those from normal children in our region. ${ }^{11}$

BMC was evaluated by single photon absorptiometry using an iodine-125 source and a direct readout system (Norland Corp. Mod. 2780). The instrument was calibrated at least once daily. The BMC was determined in the distal third of the non-dominant radius. Three to four measurements were made and an average obtained. The values of BMC (in $\mathrm{g} / \mathrm{cm}$ ) were expressed as $\mathrm{Z}$ score of the normal values from healthy Italian children. ${ }^{12}$ The $\mathrm{Z}$ score was calculated according to the equation:

$$
\mathrm{Z} \text { score }=\left(X_{1}-X_{2}\right) / \mathrm{SD}
$$

where $X_{1}=$ subject's measurement, $X_{2}=$ mean of the reference population for age and gender, and SD = standard deviation of the mean for the reference population.

Stature and BMC were also measured in a sex and age matched control group of healthy subjects seen in our clinic as outpatients. In order to adjust BMC data of patients for their statural growth, BMC values were also plotted against patient's height age (that is, against the age expected for their actual stature).

Serum calcium, phosphate, and alkaline phosphatase (ALP) were measured by colorimetric methods. Whole parathyroid hormone (PTH) was assayed by Immuno Radiometric Assay. Serum concentrations of osteocalcin were measured by specific radioimmunoassay. Our normal ranges were: calcium $8-11 \mathrm{mg} / \mathrm{dl}$, phosphate $3 \cdot 6-5 \cdot 5 \mathrm{mg} / \mathrm{dl}$, PTH $10-65 \mathrm{pg} / \mathrm{ml}$. Normal ranges of ALP differed with age: from 170-961 IU/1 at one year to 213-1067 IU/1 at 13-15 years. Normal osteocalcin values also varied according to age and sex (one year: males 63 (SD 16) ng/ml, females 63 (19) ng/ml; 16 years: 71 (38) ng/ml for males and 39 (13) $\mathrm{ng} / \mathrm{ml}$ for females).

A 24 hour dietary recall was collected from all patients and control subjects with the aid of a visual recording system ${ }^{13}$ which comprised

$B M C$ values of $20 \mathcal{Y R A}$ patients, both together and divided in subgroups

\begin{tabular}{|c|c|c|c|c|c|}
\hline & $\begin{array}{l}\text { All YRA } \\
\text { patients } \\
(n=20)\end{array}$ & $\begin{array}{l}S \\
(n=4)\end{array}$ & $\begin{array}{l}P \\
(n=9)\end{array}$ & $\begin{array}{l}O \\
(n=7)\end{array}$ & $\begin{array}{l}S+P \\
(n=13)\end{array}$ \\
\hline \multirow{3}{*}{$\begin{array}{l}\text { BMC } \\
\text { Z score }\end{array}$} & $-1.5(0.8)^{\star \star}$ & $-4 \cdot 9(2)$ & $-1(0 \cdot 6)^{\star}$ & \multirow[t]{3}{*}{$0.34(0.7)$} & \multirow[t]{3}{*}{$-2 \cdot 1(0 \cdot 7)^{\star \star}$} \\
\hline & \multicolumn{3}{|c|}{$p=0.05$} & & \\
\hline & & & $p=0.038$ & & \\
\hline $\begin{array}{l}\text { BMC }+ \\
\text { Z score }\end{array}$ & $-0 \cdot 6(0 \cdot 3)$ & $-1(0 \cdot 8)$ & $-0.9(0.4)$ & $0 \cdot 1(0 \cdot 6)$ & $-0.96(0.35)^{\star \star}$ \\
\hline
\end{tabular}

Values are mean (SEM). $S=$ Systemic JRA; $\mathrm{P}=$ polyarticular JRA; $\mathrm{O}=$ oligoarticular JRA. †Adjusted for height age. Significant differences compared with controls: ${ }^{\star} p<0.05 ;{ }^{\star \star} p<0.02$. pictures of different food portions. Nutrient intakes were assessed by a computer code based on available data (Dietosystem, Milano) and expressed as percent of recommended daily allowances (RDA). ${ }^{14}$ At least one other dietary recall had been obtained from the patients, four to nine months before the study. There was no significant difference in intake of any nutrients at the different evaluations.

For analysis of BMC data, the patients were further divided into subgroups: $S, P, O, S+P$, $S+P$ with wrist arthritis, and $S+P$ without wrist arthritis. Differences between mean values were examined using the KruskallWallis test and relations between series of values were examined by the Spearman test. $\mathrm{p}<0.05$ was considered significant.

\section{Results}

BMC was $0.4(0.3) \mathrm{Z}$ scores in the control group. The table shows the values of BMC and of BMC adjusted for height age in the group and subgroups of patients. BMC of all JRA patients was significantly less than in control subjects, although no significant difference in $B M C$ values was found between $S, P$ and $O$ subgroups of patients and the control group. Taking $\mathbf{S}+\mathbf{P}$ patients together, their BMC adjusted for height also was significantly less than in the controls (table). Six patients (three in group $S$, two in group $P$ and one in group $O$ ) and none of the control group had $B M C$ values less than $-2 \mathrm{Z}$ score. $B M C$ values for patients with systemic JRA were significantly less than those of patients with poly or oligoarticular JRA (table).

HSDS were $0.5(0.3)$ in control subjects and $-0.5(0.4)$ in the JRA patients $(\mathrm{p}=0.052)$.

Five patients (four group $S$ and one group P) and none of the controls had HSDS values less than -2 . HSDS were $-2 \cdot 4(0 \cdot 8)$ in group $S,-0.5(0.4)$ in group $P$ and $0.7(0.2)$ in group $\mathrm{O}$ patients. Significant differences in HSDS were found between groups $S$ and $O$ $(p=0.007), S$ and $P(p=0.03)$, and $P$ and $O$ $(\mathrm{p}=0.005)$.

Taking all JRA patients together, a significant relationship $(\rho=0.57 ; p=0.009)$ was found between BMC and HSDS. Age and HSDS were significantly related $(\rho=-0 \cdot 6$; $p=0.005)$ while no significant relationship $(\rho=-0 \cdot 1 ; p=0.6)$ was found between age and BMC.

The BMC adjusted for height age in all JRA patients, in group $P$ and in $S+P$ patients was significantly smaller than in controls (table).

BMC in the five patients from groups $S$ and $\mathrm{P}$ with wrist arthritis was $-4(1 \cdot 5) \mathrm{Z}$ score; in the eight patients from those groups who had no wrist arthritis it was $-1 \cdot 1(0 \cdot 4)(\mathrm{p}=0 \cdot 012)$. For the latter group, this BMC value was significantly smaller $(p=0.036)$ than that in the control group.

Calcium, phosphate and osteocalcin values were normal in all patients. Osteocalcin values were in the range $27-105 \mathrm{ng} / \mathrm{ml}$ (mean 90.7). ALP was above the normal range in six patients (two in group $S$, two in group $P$ and two in group O). PTH was increased in one group $S$ 
and one group $\mathrm{O}$ patient. No significant relationship was found between calcium, phosphate, ALP, PTH, or osteocalcin values and $B M C$ or HSDS. Nutrient intakes (in percent of RDA) in patients and in the control group were, respectively: calories $88.3(7) \%$ and 93.8 (5)\% (NS); proteins $121(12) \%$ and $121 \cdot 8$ (9)\% (NS); calcium $89.6(11) \%$ and 95.4 (12)\% (NS), phosphate $135.5(16) \%$ and $122 \cdot 8$ (11)\% (NS). No significant relation was found between calcium or phosphate intakes and BMC.

\section{Discussion}

Studies on BMC of JRA patients have utilised single $^{46}$ or dual $^{58}$ beam photon absorptiometry and both techniques have been shown to be able to detect reduced BMC in these subjects. Dual photon absorptiometry is more appropriate for measuring trabecular bone, but no database exists for dual photon absorptiometry in normal children in our population.

Our study has demonstrated that JRA patients have significantly reduced BMC even in absence of steroid therapy. This finding agrees with the suggestions of Lovell et $\mathrm{al}^{4}$ and with Compston et $a l^{15}$ who demonstrated a reduction in bone formation rates in adults with RA before the use of steroids. A recent study on adult $\mathrm{RA}^{3}$ also showed the strong influence of disease activity and functional capacity on BMC.

Most of our patients had taken indomethacin, which has been shown to influence bone remodelling and osteoid deposit in experimental arthritis. ${ }^{16}$ However, this effect is limited to the affected joints and it is hard to attribute the reduced BMC of JRA patients to indomethacin therapy.

The reduction in BMC was very apparent in patients with systemic JRA and, to a lesser degree, in those with polyarticular JRA, while patients with the oligoarticular form had a normal average BMC. The reduction in BMC was significant for all the JRA patients taken together and for the polyarticular subgroups and the combined systemic and polyarticular groups of patients. After adjustment for statural growth only in the combined groups $S$ and $\mathrm{P}, \mathrm{BMC}$ was significantly less than that in controls. The BMC of patients with systemic JRA was not significantly less than that of controls, probably because of the small number of subjects (table). Similarly, statural growth retardation is more pronounced in systemic JRA than in polyarticular JRA, while oligoarticular JRA patients have normal stature. Obviously age, the number of joints involved, duration of the disease, the number and duration of relapses, and the location and number of permanently affected joints may all be factors affecting the extent of bone demineralisation and slowing down of statural growth. These variables cannot be isolated in a study of limited sample size.

In the present study, BMC was measured on the distal third of the non-dominant radius. Arthritis of the wrist might affect radial BMC via local bone loss, therefore we made a separate analysis of the BMC of patients with and without wrist arthritis at the time of the study or in the past. BMC in systemic and polyarticular JRA patients with wrist arthritis was significantly less than in those without wrist arthritis. However, BMC of the same groups but without wrist arthritis was significantly less than in controls. With our study sample size, other factors possibly affecting bone accretion cannot be accounted for, but our data suggest that, while local bone loss caused by wrist arthritis can affect radial BMC, a systemic effect of the disease on BMC is operating also.

It is noteworthy that, although BMC and HSDS are significantly related, the degree of bone demineralisation (average $\mathrm{BMC}=-1.5$ $\mathrm{Z}$ scores) was much greater than the degree of statural delay (average HSDS $=-0.5$ ) in our series.

We found no relationships between BMC and serum calcium, phosphate, ALP, and PTH; indeed, calcium and phosphate values were normal in all of our patients, and PTH was increased in only two of them.

Reed et $a l^{6}$ reported reduced serum concentrations of osteocalcin (a marker of bone formation) in children with clinically active rheumatic disase; this normalised with cessation of the disease. Serum osteocalcin values did not correlate with the dose of corticosteroid administered. In contrast, we have found normal serum concentrations of osteocalcin in all active JRA patients. The significance of serum osteocalcin in active JRA thus remains to be clarified. Indeed, studies on adults with $\mathrm{RA}$ have revealed reduced, ${ }^{17}$ increased $^{18}$ or no change ${ }^{19}$ in the circulating osteocalcin concentrations.

Reduced intake of calcium, calories, or both, has been reported in children with JRA. In our patients, average intakes of calcium and calorie were less than $90 \%$ of RDA, although they did not significantly differ from those in the control group. Decreased appetite during the acute phase of the disease may be one of the causes of reduced nutrient intake. Heightened disease symptoms after intake of dairy products has been reported both in patients with $\mathrm{RA}^{23}$ and in those with JRA, ${ }^{24}$ but the reason for that was not investigated. In common with Lovell et al, ${ }^{4}$ we found no relationship between calcium intake and BMC.

Calcium and vitamin $\mathrm{D}$ supplementation have been shown to be beneficial in BMC in a limited number of steroid treated JRA patients. $^{5}$ However, hypercalciuria is a common finding in JRA subjects ${ }^{25}$ and was also found in a previous investigation of most of the patients considered in the present study. ${ }^{26} \mathrm{It}$ would be tempting to supplement the diet of non-steroid-treated JRA patients with calcium and vitamin $\mathrm{D}$, but the danger of worsening hypercalciuria and thereby risking nephrolithiasis or nephrocalcinosis has to be kept in mind. At present, we must focus our efforts on improving the efficacy of NSAID and physical therapy to counteract the bone demineralising effects of JRA. 
Adult RA is usually associated with osteoporosis. It is known that the frequency of fractures in the aged population mostly depends upon the peak bone mass that an individual achieves during adolescence. ${ }^{27}$ Therefore, the bone demineralisation which begins in JRA predisposes to even more serious bone disease in the elderly. Taking into account that JRA may itself cause bone demineralisation, the effects of steroids upon bone should be considered to be additive to those associated with the disease and use of these drugs should be regarded with even more caution.

1 Elsasser U, Wilkins B, Hesp R, Thurnam D I, Reeve J, Ansell B M. Bone rarefaction and crush fractures in juvenile chronic arthritis. Arch Dis Child 1982; 57: 377-80.

2 Schaller J G. Corticosteroids in juvenile rheumatoid arthritis. Arthritis Rheum 1977; 20: 537-40.

3 Laan R F J M, Buijs W C A M, Verbeek A L M, et al. Bone mineral density in patients with recent onset rheumatoid arthritis: influence of disease activity and functional capacity. Ann Rheum Dis 1993; 52: 21-6.

4 Lovell D, Gregg D, Heubi J, Levinson J. Bone mineralization in JRA patients. Arthritis Rheum 1986; S67: 29 .

5 Warady D B, Lindsley C B, Lukert B P, Robinson R C. Calcium and vitamin $\mathrm{D}$ supplementation in pediatric osteoporotic patients with rheumatic disease Arthritis Rheum 1989; S32: 29 .

6 Reed A, Haugen M, Pachman L M, Langman C B. 25 -Hydroxyvitamin D therapy in children with active juvenile rheumatoid arthritis: short-term effects on serum osteocalcin levels and bone mineral density. 7 Pediatr osteocalcin levels an

7 Bardare $M$, Bianchi $M$ L, Furia $M$, Gandolini G G, Cohen E, Montesano A. Bone mineral metabolism in juvenile chronic arthritis: the influence of steroids. Clin Exp Rheumatol 1991; S6: 29-31.

8 Hopp R, Degan J, Callagher J C, Cassidy J T. Estimation of bone mineral density in children with juvenile rheumatoid arthritis. F Rheumatol 1991; 18: 1235-9.

9 Rodman G P, Schumacher H R, eds. Primer on the rheumatic diseases, 8th edn. Atlanta: Arthritis Foundation, 1983; $97-103$.
10 Tanner J $M$, Whitehouse $\mathrm{R} \mathrm{H}$. Clinical longitudinal standards for height, weight, height velocity, weight
velocity, and stage of puberty. Arch Dis Child 1976; 51: velocity,

11 Greco L, Mayer M, Grimaldi M, Capasso G. Factors affecting growth in Campania's schoolchildren. Acta Med Auxol 1982; 14: 177-87.

12 Saggese G, Federico G, Ghizzi P, Cipriani J, Bertelloni S, Igli Baroncelli G. Densitometria ossea in età pediatrica. Valori normali tra 2 e 19 anni. Primi dati italiani. Minerva Pediatr 1986; 38: 545-51.

13 Istituto Scotti Bassani. Atlante ragionato di alimentazione. Milano, 1989.

14 Food and Nutrition Board, National Academy of Sciences, National Research Council. Recommended daily allowances. Nutrition Reviews 1990; 48: 28-30.

15 Compston J E, Crawley E O, Evans C, O'Sullivan M M. Spinal trabecular bone mineral content in patients with non-steroid treated rheumatoid arthritis. Ann Rheum Dis 1988; 47: 660-4.

16 Pettipher E R, Henderson B, Edwards J C, Higgs G A Effect of indomethacin on swelling, lymphocyte influx and cartilage proteoglycan depletion in experimental arthritis. Ann Rheum Dis 1989; 48: 623-7.

17 Ekenstam E A F, Ljunghall S, Hallgren R. Serum osteocalcin in rheumatoid arthritis and other inflammatory arthritides: relation between inflammatory activity and the effect of glucocorticoids and remissioninducing drugs. Ann Rheum Dis 1986; 45: 484-90.

18 Gevers G, Devos P, De Roo M, Dequeker J. Increased levels of osteocalcin (serum bone Gla-protein) in rheumatoid arthritis. Br f Rheumatol 1986; 25: 260-2.

19 Hermann E, Aeschlimann A, Muller W. Serum osteocalcin in chronic polyarthritis in stage III. $Z$ Rheumatol $1987 ; 46$ : in chron $129-31$.

20 Haugen $M$ A, Hoyeraal $\mathrm{H} \mathrm{M}$, Larsen S, Gilboe I M, Trygg $K$. Nutrient intake and nutritional status in children with juvenile chronic arthritis. Scand $\mathcal{f}$ Rheumato 1992; 21: 165-70.

21 Miller M L, Chacko J A, Young EA. Dietary deficiencies in children with juvenile rheumatoid arthritis Arthritis Care Res 1989; 2: 22-4.

22 Bacon M C, White P H, Raiten D J, et al. Nutritional status and growth in juvenile rheumatoid arthritis. Semin Arthritis Rheum 1990; 20: 97-106.

23 Haugen M, Kjeldsen-Kragh J, Nordvag B-Y, Forre O. Die and disease symptoms in rheumatic diseases - Results of a questionnaire based survey. Clin Rheumatol 1991; 10 401-7.

24 Ratner D, Eshel E, Vigder K. Juvenile rheumatoid arthritis and milk allergy. $\mathcal{F} R$ Soc Med 1985; 78: 410-3.

25 Stapleton F B, Hanissian A S, Miller L A. Hypercalciuria in children with juvenile rheumatoid arthritis: association with hematuria. Pediatrics 1982; 69: 594-7.

26 Strano C G, Maresca N, Torino G. Escrezione urinaria di calcio in bambini affetti da artrite cronica giovanile. Ped Oggi Med Chir 1989; 10: 266-8.

27 Boyle I T. Bones for the future. Acta Paediatr Scand 1991 S373: $58-65$. 